NASA Technical Memorandum 100796

\title{
Relationship Between Fatigue Life in the Creep-Fatigue Region and Stress-Strain Response
}

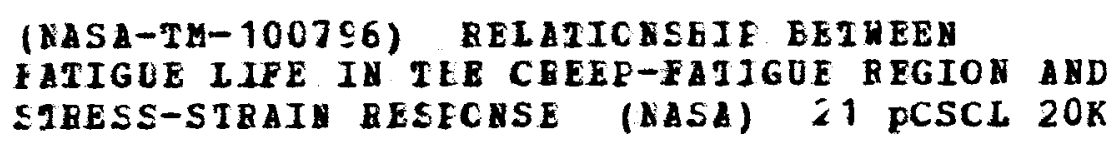

\section{A. Berkovits \\ Lewis Research Center \\ Cleveland, Ohio}

and

S. Nadiv

Technion-Israel Institute of Technology

Haifa, Israel

Prepared for the

VI International Congress on Experimental Mechanics sponsored by the Society of Experimental Mechanics Portland, Oregon, June 5-10, 1988 


\title{
RELATIONSHIP BETWEEN FATIGUE LIFE IN THE CREEP-FATIGUE \\ REGION AND STRESS-STRAIN RESPONSE
}

\author{
A. Berkovits* \\ National Aeronautics and Space Administration \\ Lewis Research Center \\ Cleveland, Ohio 44135 \\ and \\ S. Nadiv ${ }^{\dagger}$ \\ Technion - Israel Institute of Technology \\ Department of Materials Engineering \\ Haifa, Israel
}

\begin{abstract}
On the basis of mechanical tests and metallographic studies, strainrange partitioned lives were predicted by introducing stress-strain materials parameters into the Universal Slopes Equation. This was the result of correlating fatigue damage mechanisms and deformation mechanisms operating at elevated temperatures on the basis of observed mechanical and microstructural behavior. Correlation between high-temperature fatigue and stress-strain properties for nickel-base superalloys and stainiess steel substantiated the method. Parameters which must be evaluated for PP- and CC- life are the maximum stress achievable under entirely plastic and creep conditions respectively and corresponding inelastic strains, and the elastic modulus. For plasticity/creep interaction conditions (PC and $C P$ ) two more pairs of stress-strain parameters must be ascertained.

INTRODUCTION

Material response in high-temperature turbomachinery is controlled by deformation processes such as time-dependent creep and time-independent

\footnotetext{
${ }^{*}$ A. Berkovits National Research Council - NASA Research Associate on leave from Technion - Israel Institute of Technology, Department of Aeronautical Engineering, Haifa, Israel.

toeceased.
} 
plasticity during either tension or compression straining in the fatigue cycle. Success in estimating low-cycle fatigue life under such strongly rate-dependent deformation has varied considerably (Refs. I to 4).

One of the more successful phenomenological methods for predicting high-temperature, low-cycle fatigue life is the strainrange partitioning approach, which was developed at NASA by Manson, Halford, and Hirschberg (Ref. 5), and has become a viable engineering design tool (Saltsman and Halford (Ref. 6)). The procedure involves the experimental determination of the four basic life relationships, resulting from the four possible combinations of plastic or creep strainrange in the tensile or compressive halves of the fatigue cycle* for a given material, and their use in conjunction with an interaction damage rule to predict cyclic lives.

The present work was undertaken in order to enhance understanding of the mechanisms which are responsible for observed material response, and thereby achieve a prediction model. The research required analysis of strain-cyclic mechanical response in the light of monotonic creep and plasticity response, and metallographic determination of the plasticity and creep damage mechanisms operating during SRP fatigue loading. Finally a method for the estimation of the strain-life relations could be developed, based on the mechanical and microstructural response observed. name ly:

*Throughout the discussion strainrange partitioning notation is used,

$\begin{array}{ccc}\text { Subscripts } & \text { Tensile loading } & \text { Compressive loading } \\ \text { PP } & \text { Plasticity } & \text { Plasticity } \\ \text { CC } & \text { Creep } & \text { Creep } \\ \text { PC } & \text { Plasticity } & \text { Creep } \\ C P & \text { Creep } & \text { Plasticity }\end{array}$


In the present program, Refs. 7 to 9 , both cyclic and supporting monotonic tests were conducted on MAR-M200+2\%Hf under strain control at constant strainrates. Cyclic data on the other materials studied were found in the literature, so that only monotonic tests and supporting microscopy were required. The emphasis in this paper is on observed mechanical behavior. A more extensive discussion of microstructural response can be found in Nadiv et al. (Ref. 10).

CYCLIC AND MONOTONIC DAMAGE MECHANISMS IN MAR-M200+Hf

The initial phase of this research included an extensive mechanical and metallographic study of directionally solidified MAR-M200+2\%Hf, tested at $975{ }^{\circ} \mathrm{C}$. Strain-controlled cyclic and monotonic tests, conducted over a range of strainrates, yielded strainrange-partitioned life data and stress-strain data in both the plasticity and creep regimes. Subsequent microscopic examination of test specimens revealed the damage mechanisms operating under the various strain conditions imposed.

Monotonic Behavior

The tensile stress-strain response of MAR-M200+Hf material at $975{ }^{\circ} \mathrm{C}$ is represented by the curves in Fig. 1. Examination of the failed test specimens revealed three distinct damage mechanisms, depending on the region of strain and strainrate.

Beyond the points of maximum true stress the stress-strain curves formed a set of more or less parallel, gradually decreasing lines. This region was governed by dynamic recovery of the material. It was bounded on the left by the maximum stress developed under a given strainrate. On the right the region was bounded by the fracture strain, which was constant at the lower strainrates which characterize creep, and decreased somewhat in the high-strainrate, plasticity-affected regime. 
Plasticity was the dominant process at strainrates above $0.001 \mathrm{sec}^{-1}$ in the region before the maximum stress was attained for the given strainrate. Here the stress-strain relationship was independent of the strainrate at low inelastic strain. At these relatively high strainrates, dislocation locking akin to strain-aging did not begin to be felt until considerable strain had taken place under strain-hardening conditions. In fact, by the time strain-aging-like effects could take place in this range they were over-shadowed by the recovery process which eventually led to failure. The lower boundary of the plasticity region was defined by a time-constant, controlled by the material diffusion rate.

Dislocation generation, pile-ups and interactions, causing a hardening effect, dominated the low strainrate, low strain region of the stress-strain curves. At low strainrates, low to moderate stresses developed due to dislocation climb and diffusion processes in the material. Recovery rates at the low energy levels involved here were over-shadowed until substantial strain had been achieved. The diffusion processes were increasingly inhibited by continuing dislocation locking, with the result that as strainrate decreased the strain to achieve a given stress increased, until sufficient strain had accumulated so that recovery became the dominant cause of straining.

Thus an area where time-independent strain occurs at high-strainrates prior to initiation of the recovery process, and a region of time-dependent deformation at more moderate strainrates, were defined. Time-dependent deformation is caused by dynamic recovery in the material, evidenced as straining initiated at moderate strainrate and again when failure is approached. Between these extremes dislocation locking mechanisms retard deformation and lead to transitory hardening of the material. These characteristics of monotonic straining have been emphasized because of their significance relative to cyclic response. 


\section{Cyclic Behavior}

The cyclic response curves obtained under symmetrical strain-control $\left(R_{\varepsilon}=-1\right)$ were unique functions of loading frequency, which was constant throughout each cyclic test. For a given frequency a single family of hysteresis loops resulted, bounded by common tensile and compressive inelastic stress-strain curves, regardless of strain amplitude, for both PP and CC tests (Fig. 2). Furthermore, the plasticity half of $C P$ and $P C$ hysteresis loops coincided with PP results, while the creep half matched results obtained from CC tests. The fact that the cyclic stress-strain relationships did not change as a result of altering the strain amplitude (and accordingly the strainrate) at a given test frequency, indicates that little or no hardening occurred under cyclic loading, the material remaining almost fully recovered and soft. This suggests that radically different characteristics were active in the microstructure under cyclic and monotonic conditions, before the onset of the cracking and failure phase. Similar response under cyclic conditions was noticed previously by Berkovits (Ref. 11) for Udimet-700, as well as for 316 stainless steel.

The phenomenon of preserved "softness" of the material under cyclic conditions has also been noted by others (Kear and Oblack (Ref. 12)). It is apparently the result of relaxation of dislocation back-stress and pile-up during reverse loading, so that, following each load reversal, the material responds as if it were virgin material. In this respect, the cyclic response is quite different from monotonic behavior, a fact which will be important when fatigue life prediction is discussed in the next section.

\section{STRAINRANGE PARTITIONED LIFE PREDICTION}

The crux of the study of constitutive behavior of materials is its use in predicting failure. This objective has seldom been achieved (cf. Ross (Ref. 13)). Fatigue-life data obtained from MAR-M200+Hf material at $975{ }^{\circ} \mathrm{C}$ will be 
reviewed as the basis for the proposed method for predicting fatigue life from monotonic stress-strain behavior.

The key to cyclic-creep life prediction is to be found by interpretation of the cyclic and monotonic stress-strain response in terms of the controlling deformation process. It was stated previously that recovery-controlled deformation is defined by the negative slope of the stress-strain curves in the high-strain region, and by a line which separates the plasticity and dynamic recovery regimes at low strains. (These curves can be related to the diffusion energy relation.) The hardening process which occurs at low strains can be described as a family of curves emanating from the recovery initiation line and intersecting the recovery curves at strains corresponding to the maximum stress developed at each strainrate. The line of intersection of the two families of curves which represent the controlling processes, is significant when attention is turned to the cyclic loading case.

Under cyclic CC loading (Ref. 9), stress ranges above $600 \mathrm{MPa}$ indicated some cyclic hardening, while lower stress amplitudes exhibited slight cyclic softening. Very low frequency tests underwent hardening similar to monotonic tests at commensurate strainrates. It is significant that the observed hardening and softening rates were such that the cyclic response converged in all cases on a state-point defined by a stress-range equal to $600 \mathrm{MPa}$ and a corresponding creep strain amplitude of 0.007 . The fact that this point falls on the line of maximum stresses for given strainrates (Fig. 3), and on the recovery curve for a stress of $600 \mathrm{MPa}$, may not be coincidental. Failure of MAR-M200+Hf at $975^{\circ} \mathrm{C}$ is due to the dynamic recovery processes and occurs in the creep region at an upper stress limit of approximately $600 \mathrm{MPa}$. The recovery mechanism appears to be coarsening of $\gamma^{\prime}$ precipitate particles (Ref. 10). Although at higher stresses failure occurs after plastic deformation, it is still due to recovery. However, here the recovery 6 
mechanism is dissolution of $\gamma^{\prime}$, and ductility is reduced as a result of the earlier plastic deformation. (An extensive discussion of the microstructural developments is given in Ref. (10).)

Thus the monotonic stress and inelastic strain coordinates, $600 \mathrm{MPa}$ and 0.007 respectively, indicated in Fig. 1, are sufficient to define conditions leading to failure under the completely relaxed creep cycling, which controls CC, CP and PC failure in the directionally solidified MAR-M200+Hf material under discussion. (In most materials $C P$ and $P C$ damage mechanisms are not identical to CC mechanisms, as will be discussed presently.) On this basis, a relation of the Universal-Slopes type can be suggested as:

$$
\frac{\Delta \varepsilon}{2}=\frac{\sigma_{U C C}}{E} N^{-0.12}+\varepsilon_{U C C}^{0.6} N^{-0.6}
$$

where $\sigma_{U C C}$ is the ultimate time-dependent stress (equal to $600 \mathrm{MPa}$ in MAR-M200+Hf at $975^{\circ} \mathrm{C}$ ), and $\varepsilon_{U C C}$ is the corresponding time-dependent strain (equal to 0.007 in MAR-M200+Hf at $975^{\circ} \mathrm{C}$ ), see Fig. 3 .

The present contention, that fatigue life is determined by the material response at its maximum monotonic strength, before the onset of dynamic recovery leading to failure, can be applied to PP data as well. Maximum stress under plasticity conditions occurred in the material investigation at oupp equal to $900 \mathrm{MPa}$. The corresponding plastic strain eupp was approximately 0.007 , coincidentally the same value as for eucc. These values of the constitutive parameters were substituted in a PP relation of the form:

$$
\frac{\Delta \varepsilon}{2}=\frac{\sigma_{U P P}}{E} N^{-0.12}+\varepsilon_{U P P}^{0.6} N^{-0.6}
$$

Lifetime of strainrange partitioned tests conducted under constant strainrates are shown as symbols in Fig. 4. The PP-life results show significantly longer lives than $C C, P C$ or $C P$ results. The latter all have similar fatigue lives, because there are almost no transverse grain boundary 
segments to act as crack initiation sites under tensile creep conditions in the directionally solidified material (Manson and Halford (Ref. 14)). In all cases detectable fatigue cracks developed only during the last 20 percent of the cyclic tests. Somewhat more oxidation occurred on the crack face in tests during which the tensile phase was at low strainrate (CC and $C P$ ) than in those with high tensile strainrate ( $P P$ and $P C$ ).

Correlation of calculated results obtained from Eqs. (1) and (2), and shown as curves in Fig. 4, with CC, CP, PC as well as PP data is excellent.

\section{CP AND PC LIFE PREDICTION FOR OTHER MATERIALS}

In directionally solidified MAR-M200+Hf material, CP and PC fatigue life was dominated by the creep loading. More importantly, the plasticity half of the strain cycle did not significantly affect the response of the creep half of the hysteresis loop. As a result, the creep parameters remained the controlling factors in $C P$ and $P C$ life. However, in other materials the effect of compressive plasticity on the subsequent tensile creep half-cycle, in a CP test, and of compressive creep on subsequent tensile plasticity in a PC test, must be quantified in order to predict $C P$ and PC lifetimes from the Universal-Slopes Equation. The appropriate values of $\sigma_{U}$ and $\varepsilon_{U}$ xmay be determined from the tensile side of one-cycle-to-failure tests, in which compressive stress and strain equivalent to the negative of the maximum ( $P$ or $C$ ) stress and strain are applied prior to tensile ( $C$ or $P$ respectively) loading to failure. The life-prediction relations for $C P$ and PC conditions then become:

$$
\frac{\Delta \varepsilon}{2}=\frac{\sigma_{U C P}}{E} N^{-0.12}+\varepsilon_{U C P}^{0.6} N^{-0.6}
$$

and

$$
\frac{\Delta \varepsilon}{2}=\frac{\sigma_{U P C}}{E} N^{-0.12}+\varepsilon_{U P C}^{0.6} N^{-0.6}
$$


respectively. The validity of this approach was investigated for a number of other elevated temperature materials.

COMPARISON BETWEEN PREDICTED AND EXPERIMENTAL SRP LIFE

The key to cyclic life prediction for MAR-M200+Hf at elevated temperature was perceived by interpretation of the cyclic and monotonic mechanical response in terms of the controlling mircostructural processes. When the interaction of dynamic recovery and strain-hardening processes was understood in terms of the microstructure, a method of life prediction evolved.

Clearly, in other materials different chemomechanical processes may be responsible for strain hardening. However, the significant point is that cyclic strength persists as long as the hardening process, whatever its cause, dominates the deformation. When the hardening mechanism is superseded by recovery processes, both monotonic and cyclic resistance are essentially exhausted. Thus the stress and strain parameters obtaining at the point of mechanism-change in the monotonic test are also the controlling parameters for estimating cyclic life. These parameters are the true stress and the corresponding true strain in the plasticity and creep-range strength tests.

Evaluating these parameters in the plasticity stress-strain curve is straight-forward. However, they must also be ascertained for the (unknown) strainrate at which the full creep capability of the material is realized. In principle the required stress-strain curve is that for which the ultimate stress corresponds to the proportional limit stress of the plasticity curve. In practice, the correct curve may be better determined by taking some small plastic strain such as the 0.1 percent offset as the limit, instead of the proportional limit (Fig. 1).

In order to test the validity of the relationship between the perceived critical damage point on the stress-strain curve and strainrange partitioned life, a comparison was performed for three nickel-base superalloys and a 
stainless steel. Fatigue life data were taken from the literature for the following materials: AF2-1DA at $760^{\circ} \mathrm{C}$, Saltsman and Halford (Ref. 6); Udimet-700 at $760{ }^{\circ} \mathrm{C}$, Berkovits (Ref. 15); S.S. 316 at $705^{\circ} \mathrm{C}$, Hirschberg and Halford (Ref. 16).

For each material a series of six stress-strain tests were conducted under strain control at the appropriate temperature. The six tests consisted of:

1. High-strainrate test to define plasticity parameters;

2. Moderate-strainrate tests to define the creep region upper bound;

3. One-cycle-to-failure tests (one $C P$, one $P C$ ). Strainrates and compressive strain limit were as defined by the previous tests, so that appropriate $\varepsilon U$-strains were achieved in compression, and creep-phase strainrates were at the plasticity/creep boundary.

Fractography performed on two of the materials tested (Figs. 5 and 6) indicated that the failure-surface characteristics of the one-cycle-to-failure $C P$ and $P C$ tests corresponded to those of the tensile creep-range and plasticity-range fajlures respectively. Stress-strain curves for the materials tested are presented in Fig. 7, and parameters used in order to define the plasticity/creep boundary are shown in Fig. 8 . Values of stress and strain parameters obtained from these tests for use in the life-prediction Eqs. (1) to (4) are tabulated in Table 1. Values for MAR-M200+Hf are also included for completeness. Total strainrange against lifetime curves for the four materials calculated with the aid of Table 1 are compared with experimental data in Figs. 4 and 9 . In general the correlation supports the proposed method. Results of the comparison indicate that parameters required for Universal-Slopes prediction of SRP lifetimes can be evaluated from critical damage points of monotonic stress-strain data. 
CONCLUSION

A metallographic study of the correlation between SRP fatigue damage mechanisms, and deformation mechanisms operating in the early stages of monotonic plastic and creep ductility at elevated temperatures, evolved a method of evaluating material parameters for Universal-Slopes prediction of fatigue life. Besides the elastic modulus of the material, the required parameters are the maximum true stress and corresponding inelastic strain under the four strainrange partitioning conditions. These conditions include the strainrates which produce entirely plastic and upper creep-boundary deformations, and two one-cycle-to-failure cases which define plasticity/creep interactions. The parameters can be evaluated at a given temperature by as few as six stress-strain tests.

Comparison of predicted lifetimes with experimentally determined fatigue lives for four elevated temperature materials demonstrated that the principles on which the prediction method is based are sound.

\section{REFERENCES}

1. Fong, J.T. (ed.), "Fatigue Mechanisms." ASTM STP-675, ASTM, 1979.

2. Burke, J.J. and Weiss, V. (eds.), "Fatigue Environment and Temperature Effects." Plenum, 1983.

3. Amzallag, C., Leis, B.N. and Rabbe, P. (eds.), "Low-Cycle Fatigue and Life Prediction." ASTM STP-770, ASTM, 1982.

4. Brunetaud, R., et al. (eds.), "High Temperature Alloys for Gas Turbines 1982." D. Reidel, 1982.

5. Manson, S.S., Halford, G.R. and Hirschberg. M.H., "Creep-fatigue analysis by strain-range partitioning," Design for Elevated Temperature Environment, S.Y. Zamrik, ed., ASME, 1971, pp. 12-24.

6. Saltsman, J.F. and Halford, G.R., "Life Prediction of Thermomechanical Fatigue Using Total-Strain Version of Strainrange Partitioning (SRP)," NASA TP-2779, 1988 
7. Berkovits, A. and Nadiv, S., "Constitutive relationships for creep-fatigue in high-temperature materials, "Mechanical Behavior of Materials - IV, Vol. 1, J. Carlsson and N.G. Ohlson, eds., Pergamon, 1984, pp. 149-156.

8. Berkovits, A. and Nadiv, S., "Creep-fatigue in PWA 1422 material," Proceedings of the $V$ International Congress on Experimental Mechanics, Society for Experimental Stress Analysis, 1984, pp. 664-669.

9. Berkovits, A., "Estimation of high temperature low cycle fatigue on the basis of inelastic strain and strainrate," NASA TM-88841, 1986.

10. Nadiv, S., Berkovits, A. and Shalev, G., "Estimation of high-temperature low cycle fatigue on the basis of inelastic strain and strain rate," Fatigue Life: Analysis and Prediction, American Society of Metals, Metals Park, OH, 1986, pp. 399-404.

11. Berkovits, A., "Hodographic prediction of cyclic creep behavior," J. Aircraft, 11, 10-14, 1974.

12. Kear, B.H. and Oblak, J.M., "Deformation modes in $\gamma^{\prime}$ precipitation hardened nickel base alloys," Journal de Physique Colloque, $\underline{35}, 7-35$ to $7-45,1974$.

13. Ross, D.A., Chang, T.Y. and Thompson, R.L. (eds.), "Nonlinear Constitutive Relations for High Temperature Applications", NASA CP-2271, 1983.

14. Manson, S.S. and Halford, G.R., "Complexities of high temperature metal fatigue: Some steps toward understanding," Israel Journal of Technology, $\underline{21}, 29-53,1983$.

15. Berkovits, A., "Prediction of inelastic high temperature materials behavior by strain-rate approach," J. Eng. Mater. Technol., 96, 106-108, 1974.

16. Hirschberg, M.H. and Halford, G.R., "Use of strainrange partitioning to predict high-temperature low-cycle fatigue life," NASA TN D-8072, 1976. 
TABLE 1. - STRESS-STRAIN PARAMETERS FOR PREDICTION OF SRP FROM UNIVERAL-SLOPES EQUATION

\begin{tabular}{|l|r|r|r|r|}
\hline \multirow{2}{*}{ Parameter } & \multicolumn{5}{|c|}{ Material } \\
\cline { 2 - 5 } & MAR-M200 & AF2-10A & $U-700$ & S.S. 316 \\
\hline Temperature, C & 975 & 760 & 760 & 705 \\
$E_{\text {E MPa }}$ & 81700 & 161600 & 162700 & 111000 \\
$\sigma_{U P P}, \mathrm{MPa}$ & 900 & 1041 & 1320 & 300 \\
$\varepsilon_{U P P}$ & 0.007 & 0.006 & 0.122 & 0.080 \\
$\sigma_{U C C}, \mathrm{MPa}$ & 600 & 965 & 1060 & 300 \\
$\varepsilon_{U C C}$ & 0.007 & 0.005 & 0.135 & 0.080 \\
$\sigma_{U C P}, \mathrm{MPa}$ & 600 & 834 & 950 & 300 \\
$\varepsilon_{U C P}$ & 0.007 & 0.0115 & 0.036 & 0.020 \\
$\sigma_{U P C}, \mathrm{MPa}$ & 600 & 1062 & 1320 & 300 \\
$\varepsilon_{U P C}$ & 0.007 & 0.02 & 0.122 & 0.020 \\
\hline
\end{tabular}

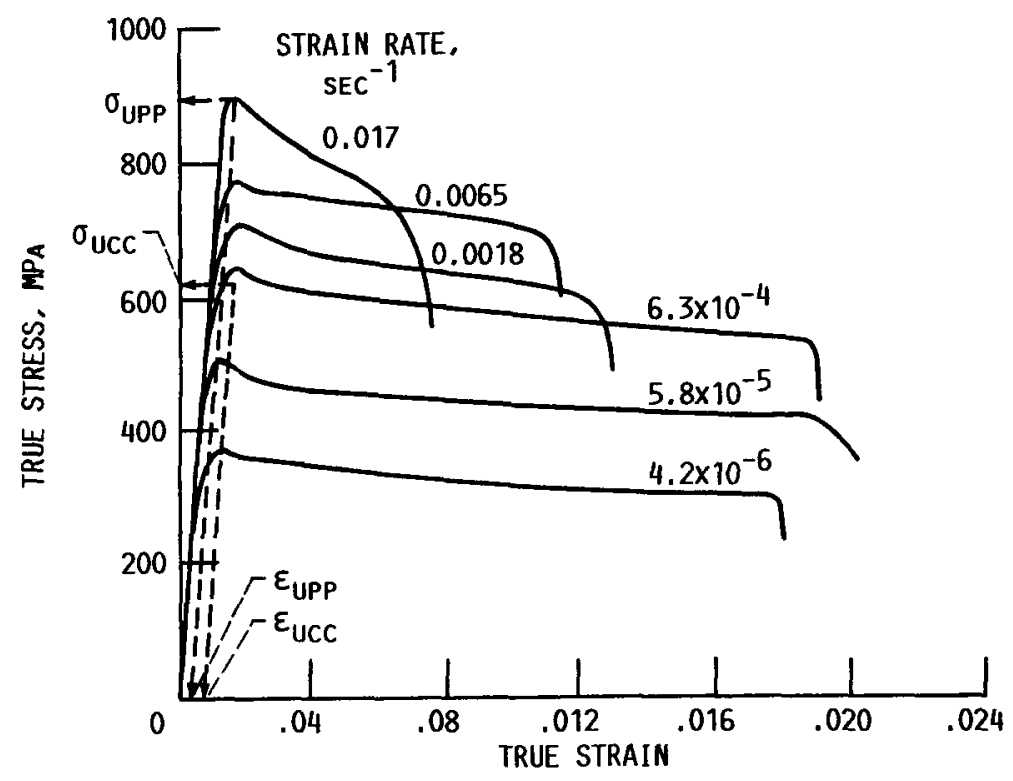

FIGURE 1. - TENSILE PROPERTIES OF MAR-M200+Hf AT $975{ }^{\circ} \mathrm{C}$. 


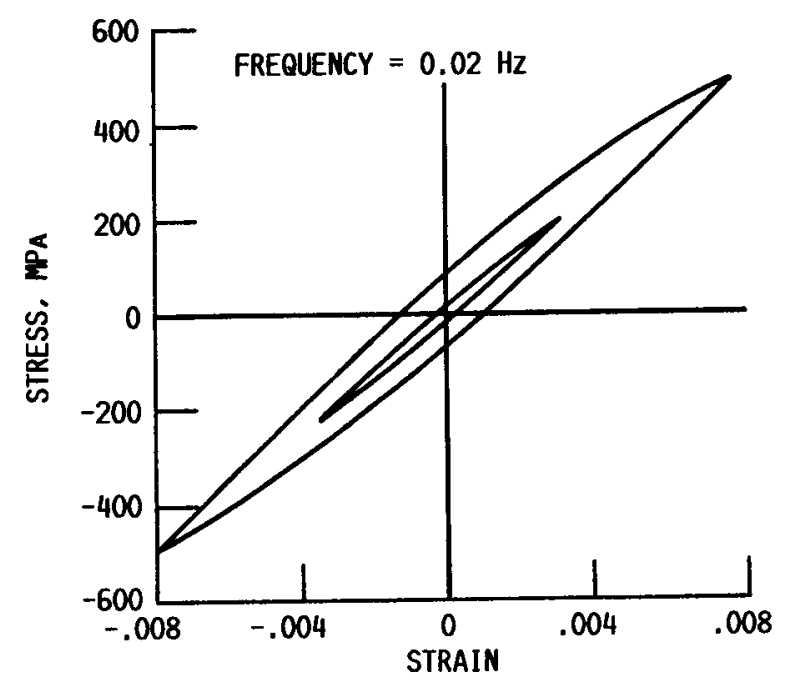

FIGURE 2. - HYSTERESIS LOOPS FOR MARM200+ HF AT $760{ }^{\circ} \mathrm{C}$.
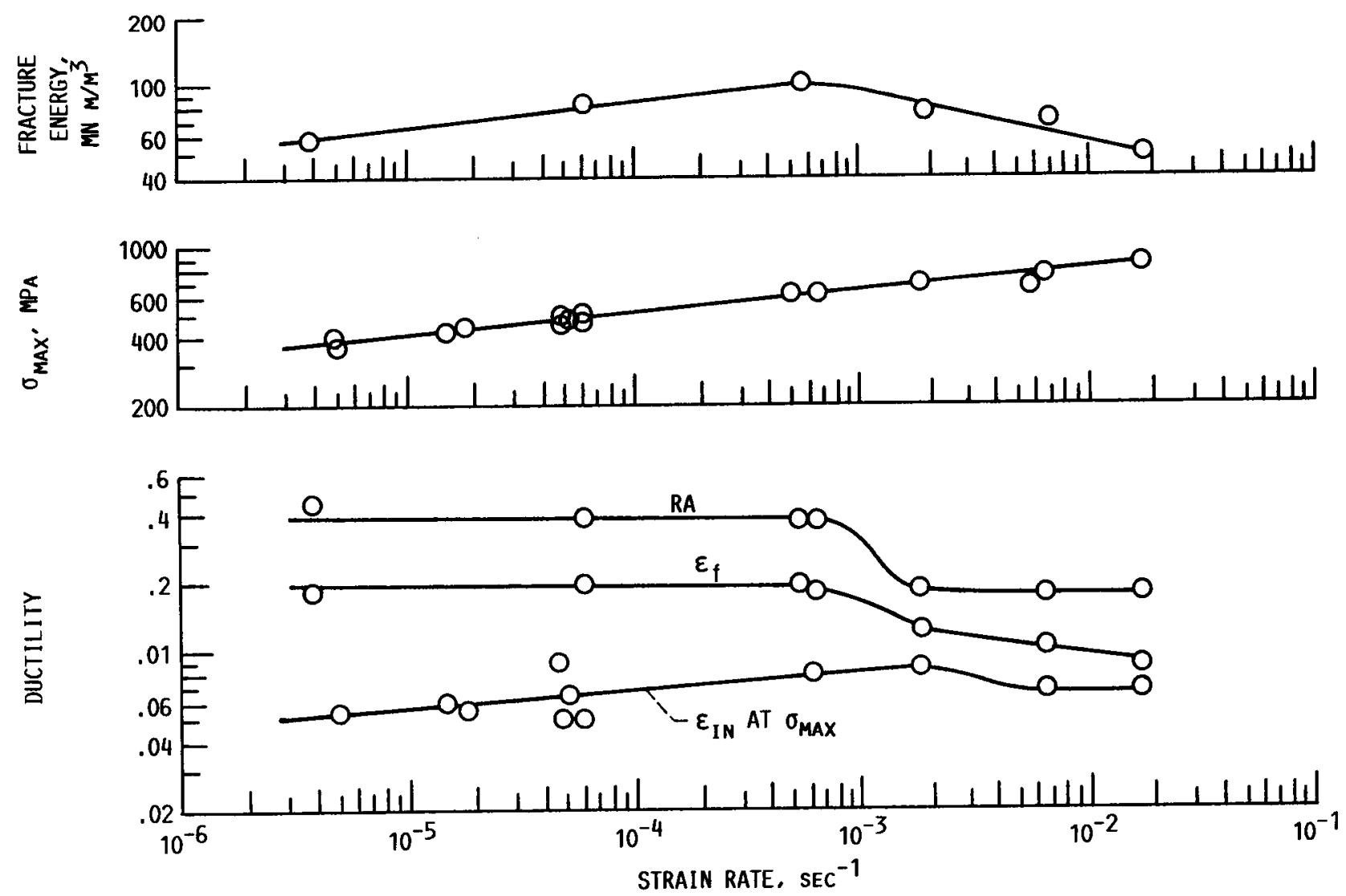

FIGURE 3. - MATERIAL PARAMETERS FOR MAR-M200+Hf AT $975{ }^{\circ} \mathrm{C}$. 
ORIGINAL PAGE IS

OF POOR QUALITY

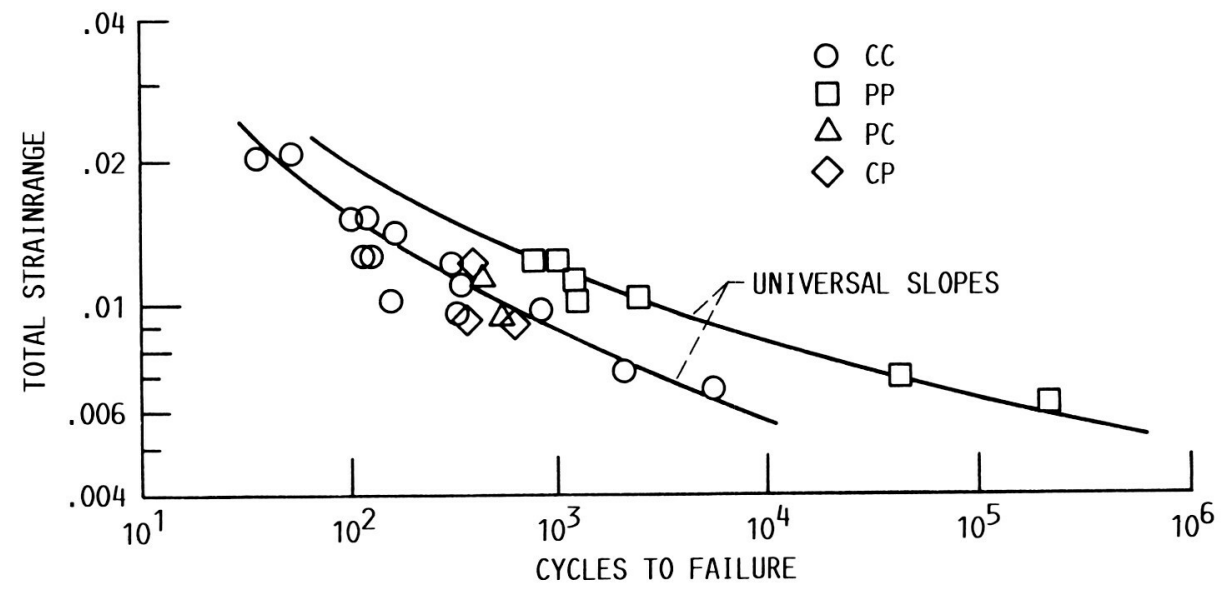

FIGURE 4. - SRP LIFETIME OF MAR-M200-Hf AT $975{ }^{\circ} \mathrm{C}$.

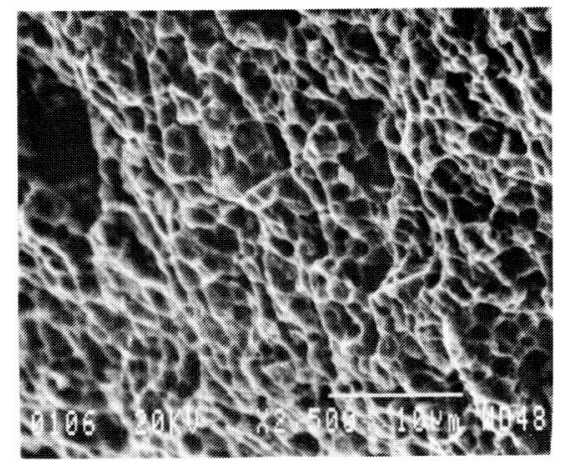

(A) PLASTIC.

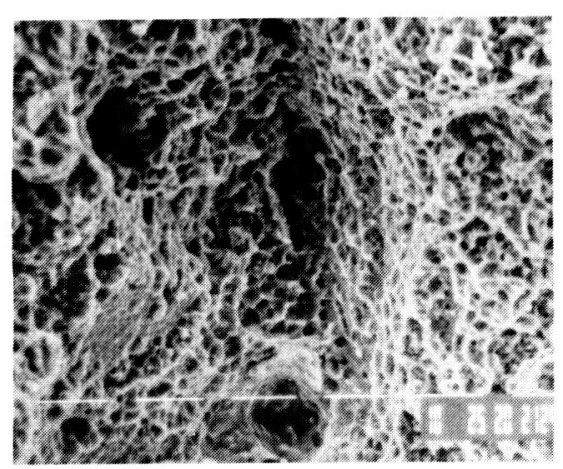

(C) ONE-CYCLE-TO-FAILURE PC.

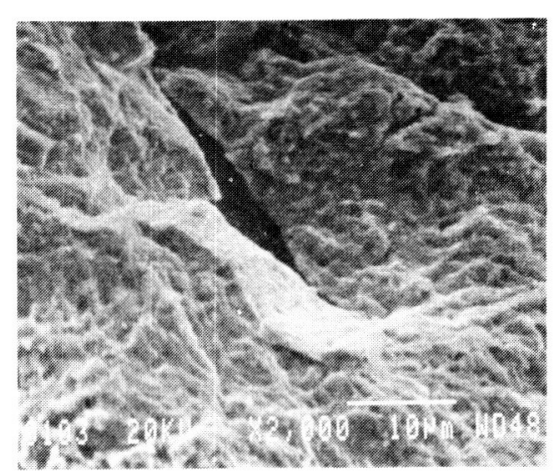

(B) CREEP-RANGE .

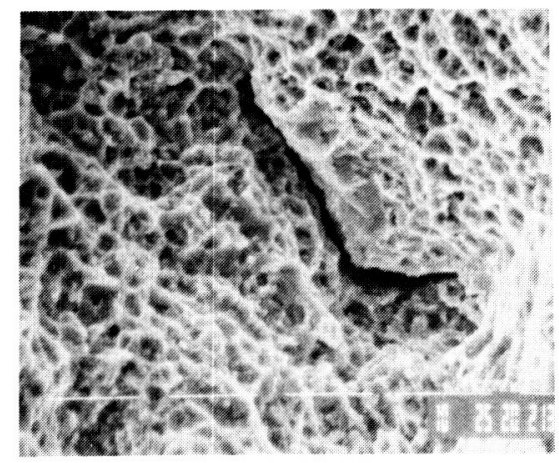

(D) ONE-CYCLE-TO-FAILURE CP. FIGURE 5. - TENSILE-TEST FAILURES OF AF2-1DA NICKEL ALLOY AT $760^{\circ} \mathrm{C}$. 


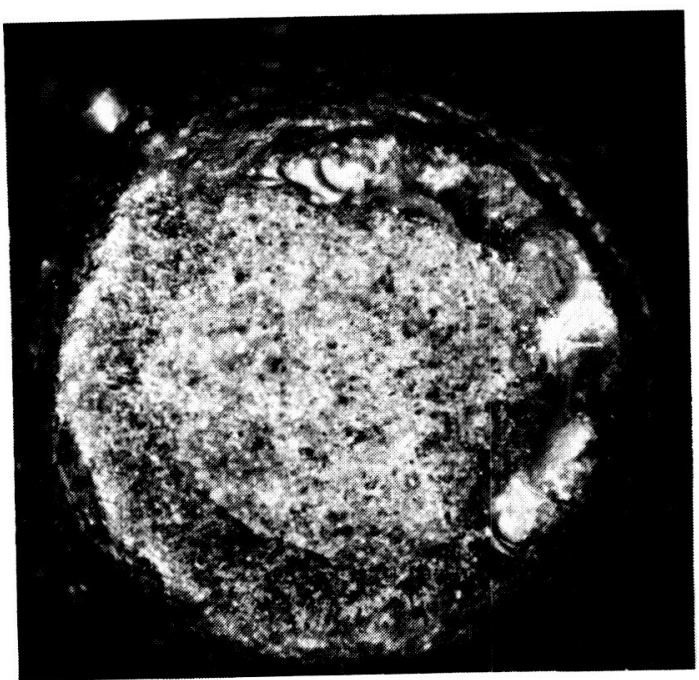

(A) PLASTIC.

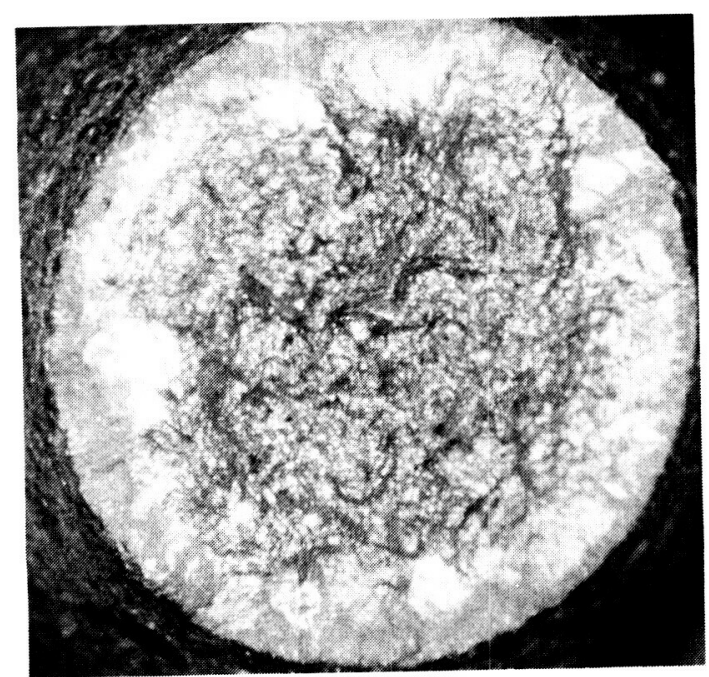

(C) ONE-CYCLE-TO-FAILURE PC.

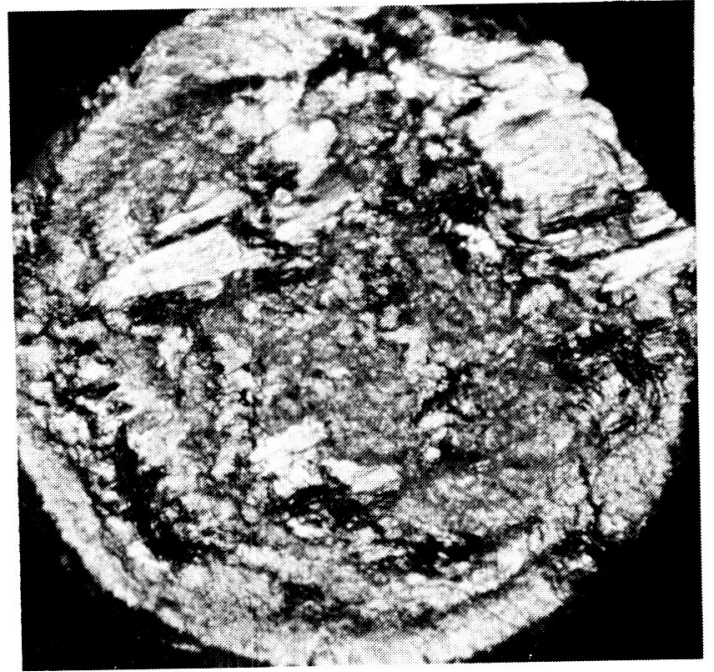

(B) CREEP-RANGE.

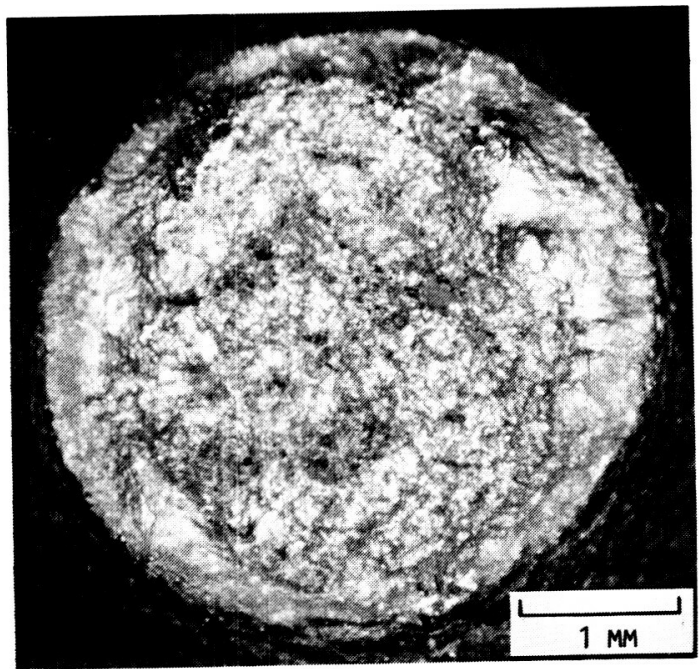

(D) ONE-CYCLE-TO-FAILURE CP. FIgURE 6. - TENSILE-TEST FAILURES OF STAINLESS STEEL 316 AT $705{ }^{\circ} \mathrm{C}$. 

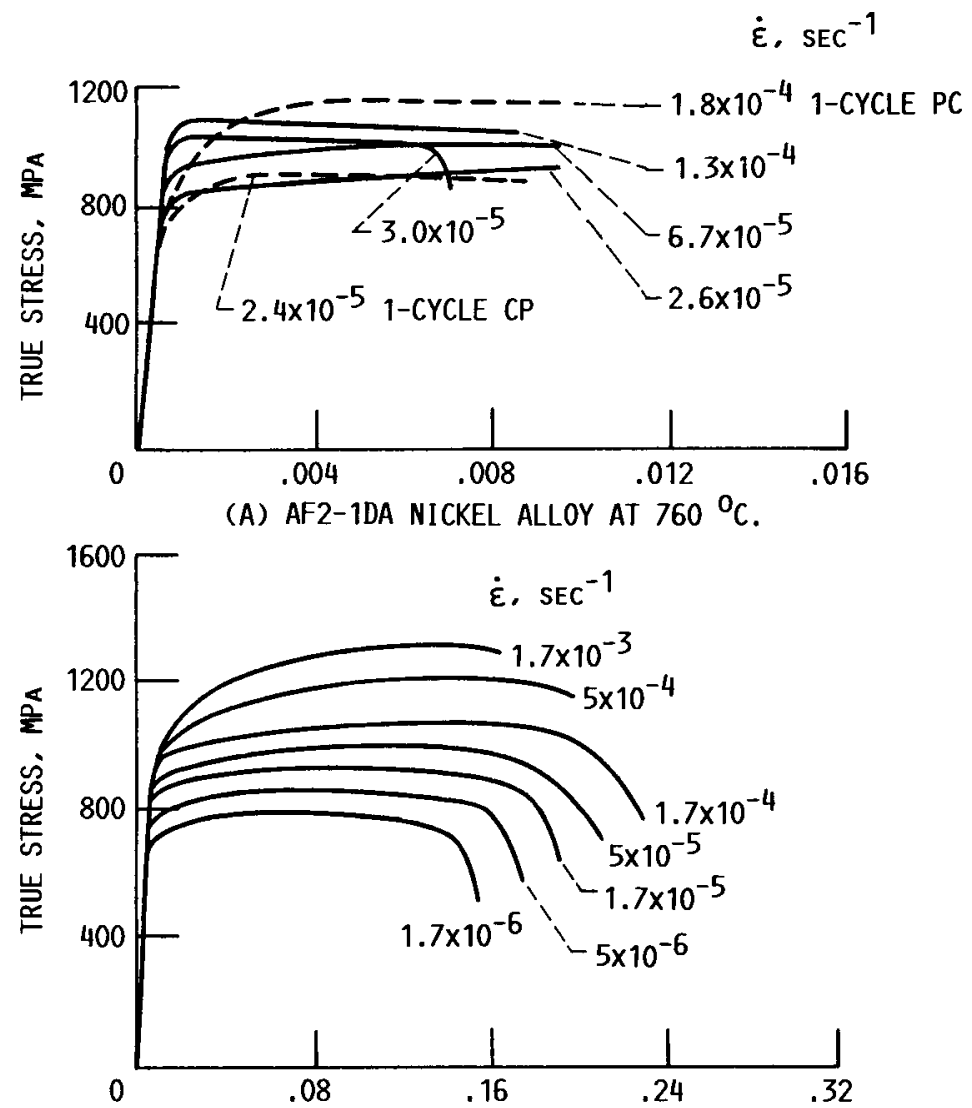

(B) UDIMET-700 NICKEL ALLOY AT $760^{\circ} \mathrm{C}$.

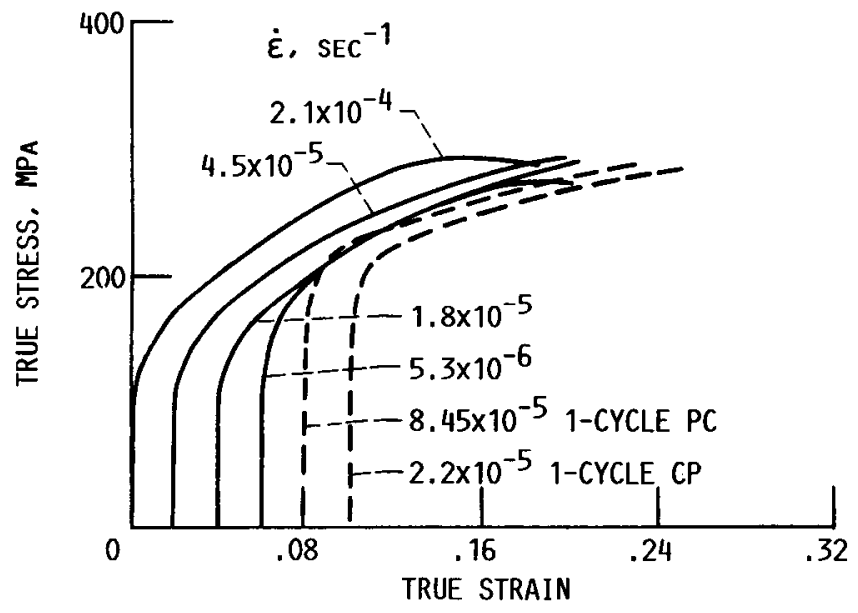

(C) STAINLESS STEEL 316 AT $705^{\circ} \mathrm{C}$.

FIGURE 7. - TENSILE STRESS-STRAIN CURVES. 


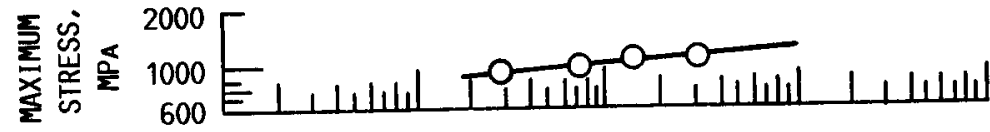

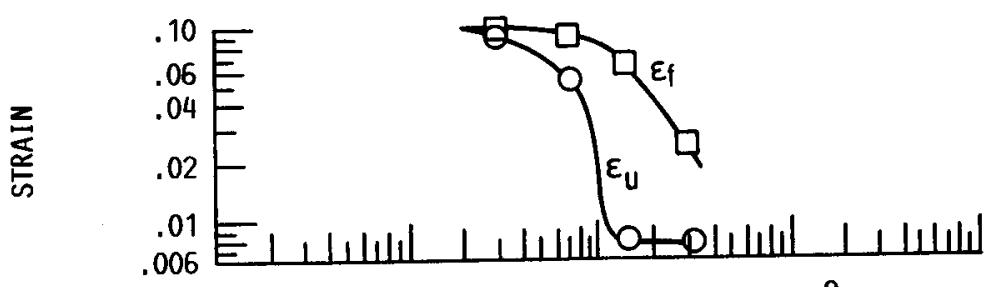

(A) AF2-1DA NICKEL ALLOY AT $760^{\circ} \mathrm{C}$.
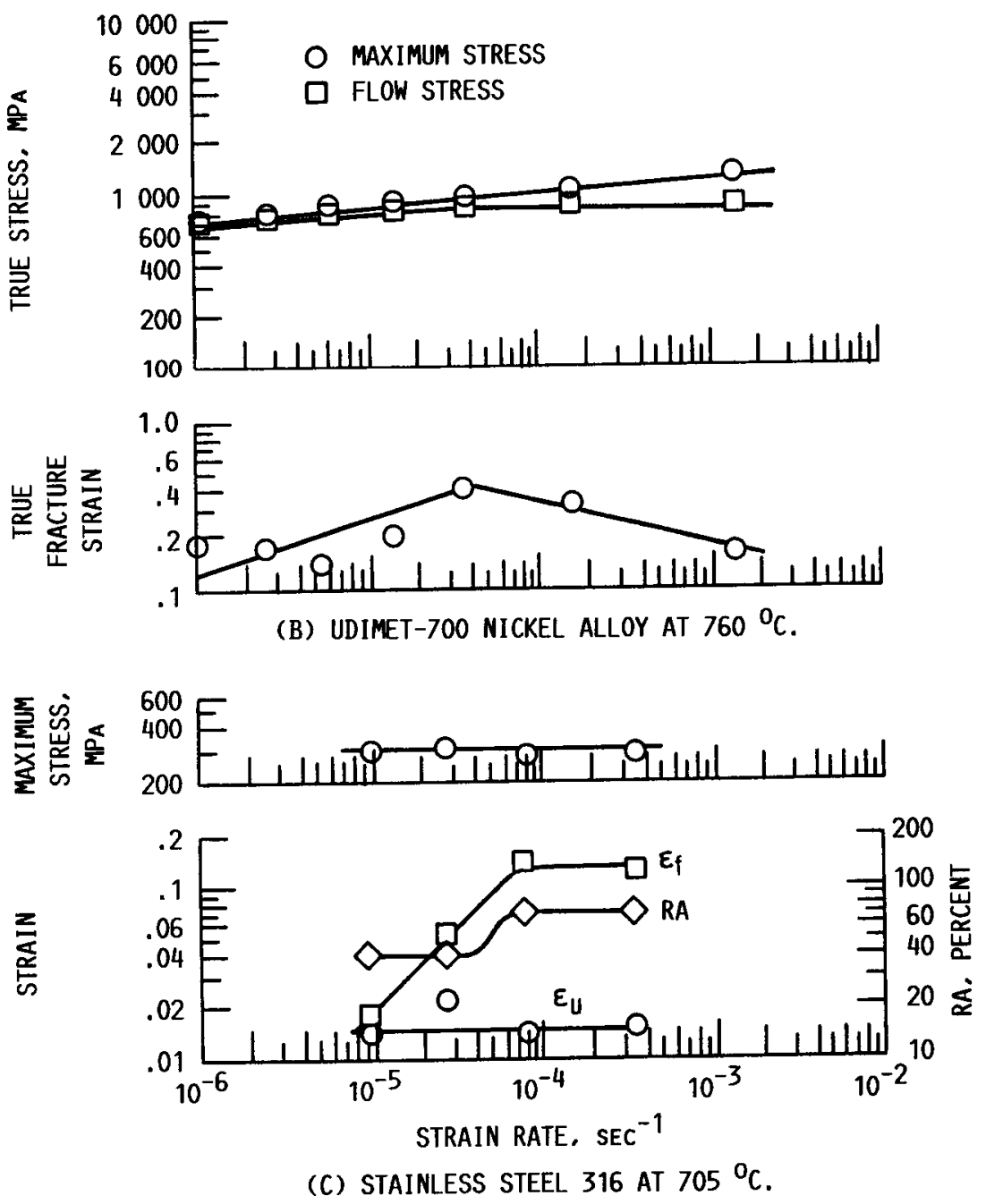

FIGURE 8. - DEFINITION OF PLASTICITY/CREEP BOUNDARY. 


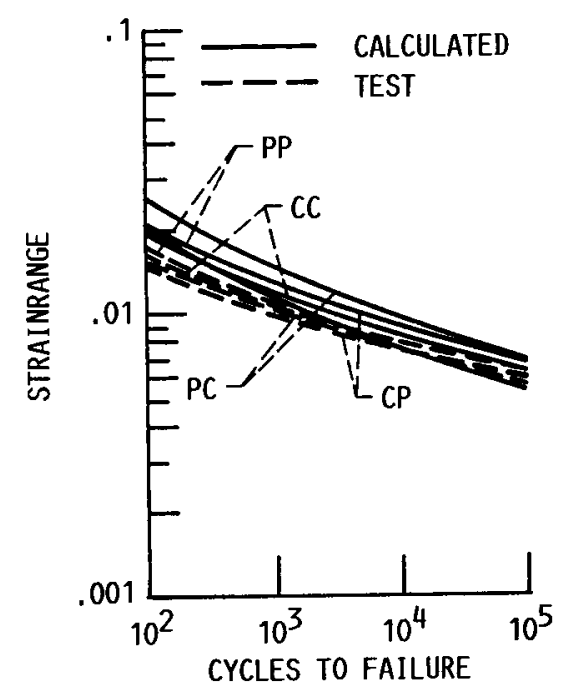

(A) AF2-1DA NICKEL ALLOY AT $760{ }^{\circ} \mathrm{C}$.

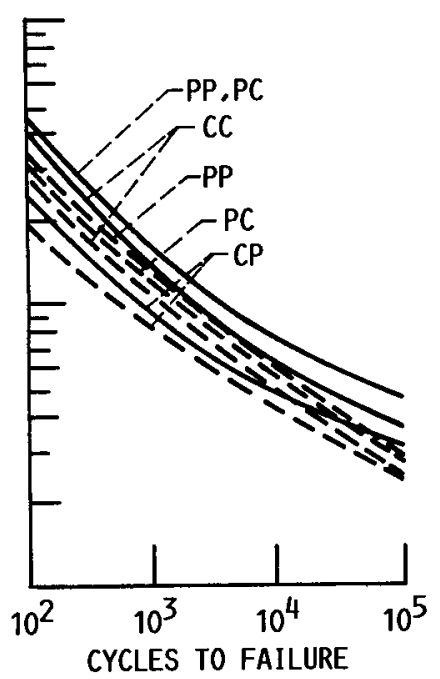

(B) UDIMET-700 NICKEL ALLOY AT $760{ }^{\circ} \mathrm{C}$.

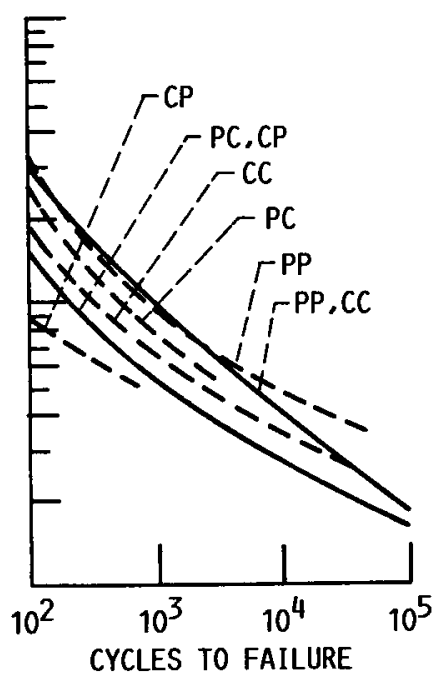

(C) STAINLESS STEEL 316 AT $705^{\circ} \mathrm{C}$.

FIGURE 9. - PREDICTED SRP LIFETIMES. 


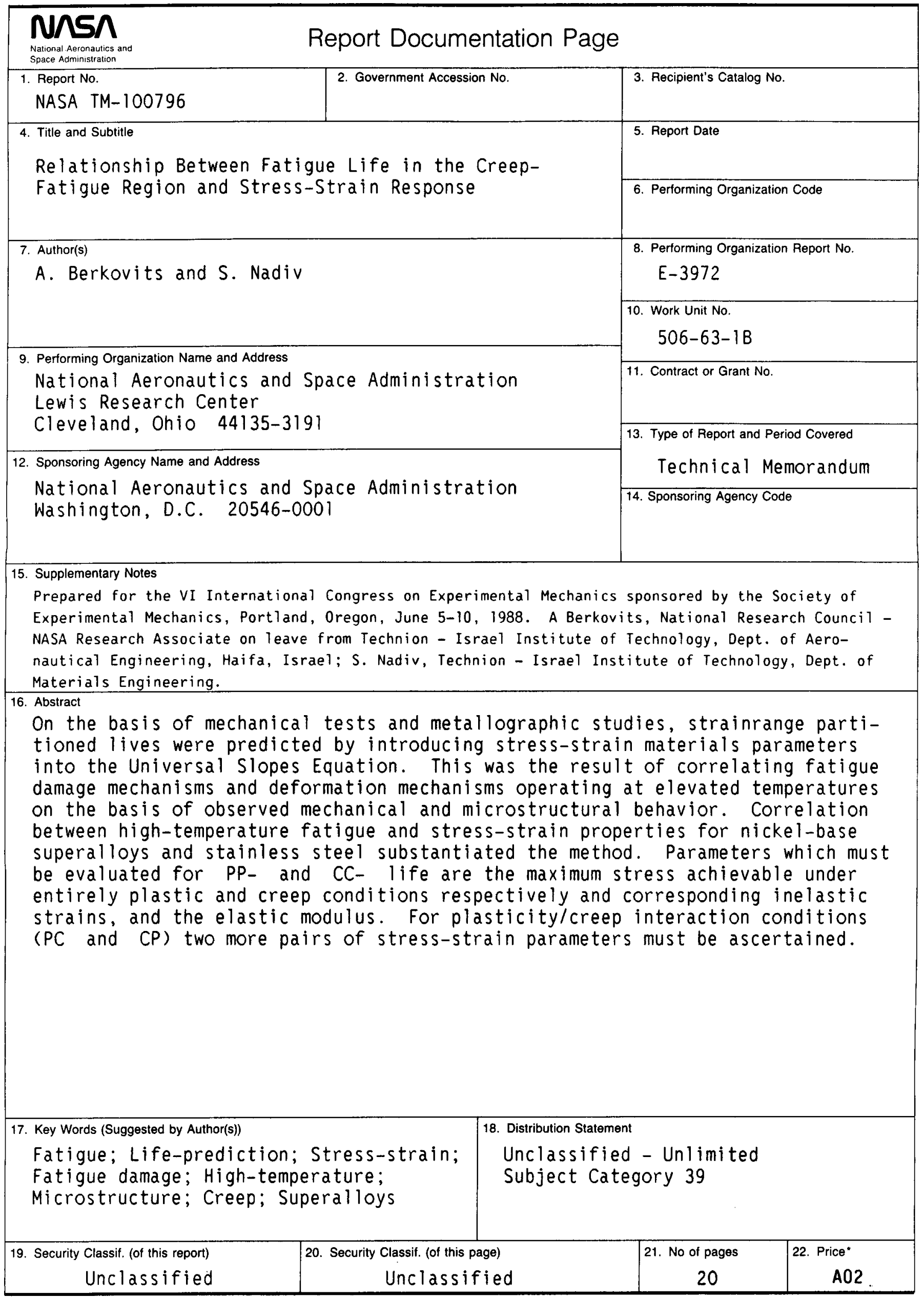

